\title{
Chronic diarrhea with renal insufficiency and electrolyte disturbances due to a large rectal polyp
}

\begin{abstract}
Large villous adenomas in the distal colon can cause chronic secretory diarrhea evolving to severe electrolyte depletion, hypovolemia and renal insufficiency. This rare clinical presentation is known as the McKittrick-Wheelock syndrome (MWS) and can lead to death if not treated adequately. The main pathophysiological mechanisms in the development of MWS are the increased mucus production by the polyp, cyclic adenosine monophosphate (cAMP) mediated potassium $(\mathrm{K}+)$, chloride $(\mathrm{Cl}-)$ and sodium $(\mathrm{Na}+)$ loss and the insufficient colon reabsorption capacity as a result of the distal location of the polyp in the colon. We report a 74 year old woman with the McKittrick-Wheelock syndrome and review previously published reports to get a deeper insight into the pathophysiological mechanisms.
\end{abstract}

Keywords: mckittrick-wheelock syndrome, chronic diarrhea, colonic polyps, rectum, kidney injury, hypokalemia, hyponatremia, endoscopic resection
Volume 6 Issue 3 - 2017

\author{
Alexander Vanden Bulcke,' Jeroen Geldof,' \\ Hans Schepkens, ${ }^{2}$ Hubert Piessevaux, ${ }^{3}$ \\ Dominiek De Wulf,' Filip Baert,' Gilbert \\ Ghillebert' \\ 'Department of Gastroenterology and Hepatology,AZ Delta \\ Roeselare-Menen, Belgium \\ ${ }^{2}$ Department of Nephrology,AZ Delta Roeselare-Menen, \\ Belgium \\ ${ }^{3}$ Department of Gastroenterology and Hepatology, Clinique \\ Universitaire Saint-Luc (UCL), Belgium
}

\begin{abstract}
Correspondence: Alexander Vanden Bulcke, Department of Gastroenterology and Hepatology, AZ Delta Roeselare-Menen, Wilgenstraat 2, 8800 Roeselare, Belgium, Tel +32 512372 I5, Fax +32 512372 17, Email alexander.vandenbulcke@azdelta.be, alexander.vandenbulcke@student.kuleuven.be
\end{abstract}

Received: January 04, 2017 | Published: March 09, 2017
Abbreviations: MWS, mckittrick-wheelock syndrome; ESD, endoscopic submucosal dissection; PAC, plasma aldosterone concentration; ARC, activated renin concentration; e.g.: Example Given; cAMP, cyclic adenosine monophosphate; PGE2, prostaglandin E2; RAAS, renin-angiotensin-aldosterone system; NSAIDS, nonsteroidal anti-inflammatory agents; COX-2, cyclo-oxygenase-2; $\mathrm{Na}+$, sodium; $\mathrm{K}+$, potassium; Cl-, chloride, $\mathrm{H}+$, hydrogen; $\mathrm{HCO}_{3}^{-}$, bicarbonate; $\mathrm{H}_{2} \mathrm{O}$, dihydrogen monoxide (water); $\mathrm{CO}_{2}$, carbon dioxide

\section{Introduction}

About $3 \%$ of all villous adenomas have a hypersecretory activity. ${ }^{1}$ Proportional to the size, these secretory polyps can produce an abundant amount of rectal discharge and consequentially can cause hypovolemia, renal insufficiency and profound electrolyte disturbances. This rare disorder is known as the McKittrickWheelock syndrome (MWS). ${ }^{1-10}$ Treatment is initially based on volume resuscitation and on correction of the electrolyte disturbances. Definitive treatment consists of endoscopic and/or surgical resection of the villous adenoma. In this article, we present a case of the MWS caused by a large rectal villous adenoma that was successfully treated by endoscopic resection. We review previously published reports to get a deeper insight into the pathophysiological mechanisms of MWS.

\section{Case presentation}

A 74year old female with unremarkable medical history except for hysterectomy, was referred to the emergency department for generalized weakness and chronic diarrhea since 4 months. The patient described her defecation as fluid, non-bloody, large volume and not improving with fasting. She did not experience abdominal pain or cramps and had no fever. She developed anorexia and weight loss of more than ten kilograms. Clinical examination at presentation showed signs of severe dehydration. Vital parameters were stable (blood pressure 104/64 $\mathrm{mmHg}$, regular heart rate 67 beats per minute) and she had no fever. Abdominal examination did not reveal any abnormalities.

Laboratory tests, including on point blood gas analysis, showed signs of inflammation, metabolic alkalosis, acute kidney injury, hyperglycemia with normal HBA1c, severe hypokalemia and hyponatremia (cfr. Table 1). Further blood analysis revealed hyperaldosteronism with a low plasma aldosterone concentration/ active renin concentration (PAC/ARC) ratio. Stool culture and serum IgA-tissue transglutaminase antibody testing were negative. Gastroduodenoscopy was normal. A colonoscopy was performed, which revealed a large, mucus-rich, villous polyp of $12 \mathrm{~cm}$ spreading semi-circumferentially along the rectal wall (Figure 1). The remaining colonic mucosa was normal and free of polyps. Based on the combined findings of the large rectal polyp, chronic diarrhea, electrolyte disturbances and dehydration, the diagnosis of McKittrick-Wheelock syndrome was made. Rigorous fluid resuscitation was started. Electrolyte disturbances were corrected by oral and intravenous supplementation in combination with spironolactone administration. A regular diabetes diet was initiated.

After metabolic stabilization, the patient underwent endoscopic resection. Endoscopic submucosal dissection (ESD) was started but was unsuccessful due to difficult visualization and incessant bleeding. During the procedure, a conversion to piecemeal resection was made. Eventually complete resection of the polyp in several fragments was obtained. The histopathological examination showed adenocarcinoma in situ (pTis) according to tumor-node-metastasis (TNM) classification. ${ }^{11}$ One day after the endoscopic procedure, the patient was discharged in good general condition and with a normalized metabolic state. The diarrhea did not reoccur and follow-up blood analysis in one month remained normal. Endoscopic evaluation was planned three months later. 
Table I Clinical and biochemical variables of individuals with overweight-obesity

\begin{tabular}{|c|c|c|}
\hline Hemoglobin & $\mid 4,6 \mathrm{~g} / \mathrm{dl}$ & Ref. $|\mathrm{I}, 8-| 5,5 \mathrm{~g} / \mathrm{dl}$ \\
\hline Leucocytosis & $13.28 \times 103 / \mathrm{mm}^{3}$ & Ref. $4,20-9,80 \times 103 / \mathrm{mm}^{3}$ \\
\hline Platelet count & $360 \times 103 / \mathrm{mm}^{3}$ & Ref. $162-351 \times 103 / \mathrm{mm}^{3}$ \\
\hline Sodium & $119 \mathrm{mmol} / \mathrm{L}$ & Ref. I33-145mmol/L \\
\hline Osmolality & $276 \mathrm{mOsm} / \mathrm{kg}$ & Ref. $280-295 \mathrm{mOSm} / \mathrm{kg}$ \\
\hline Potassium & $2,0 \mathrm{mmol} / \mathrm{L}$ & Ref. 3,5-5, I mmol/L \\
\hline Chloride & $64 \mathrm{mmol} / \mathrm{L}$ & Ref. $95-108 \mathrm{mmol} / \mathrm{L}$ \\
\hline Bicarbonate $\left(\mathrm{HCO}_{3}-\right)$ & $30,6 \mathrm{mmol} / \mathrm{L}$ & Ref. $22-29 \mathrm{mmol} / \mathrm{L}$ \\
\hline Phosphate & $\mathrm{I}, 33 \mathrm{mmol} / \mathrm{L}$ & Ref. $0,77-1,45 \mathrm{mmol} / \mathrm{L}$ \\
\hline Calcium & $2,47 \mathrm{mmol} / \mathrm{L}$ & Ref. $2,15-2,55 \mathrm{mmol} / \mathrm{L}$ \\
\hline Magnesium & $\mathrm{I}, 47 \mathrm{mmol} / \mathrm{L}$ & Ref. $0,74-0,95 \mathrm{mmol} / \mathrm{L}$ \\
\hline Urine sodium & $<20 \mathrm{mmol} / \mathrm{L}$ & I \\
\hline Urine potassium & $21 \mathrm{mmol} / \mathrm{L}$ & l \\
\hline Glucose (POC arterial bloodgas) & $240 \mathrm{mg} / \mathrm{dl}$ & Ref. $65-110 \mathrm{mg} / \mathrm{dl}$ \\
\hline $\mathrm{pH}$ (POC arterial bloodgas) & 7,63 & Ref. 7.34-7.47 \\
\hline $\mathrm{HbAlc}$ & $5,9 \%$ & Ref. $4,5-6 \%$ \\
\hline Blood urea nitrogen (BUN) & $178 \mathrm{mg} / \mathrm{dl}$ & Ref. $\mid 7-48 \mathrm{mg} / \mathrm{dl}$ \\
\hline Creatinine & $3,5 \mathrm{mg} / \mathrm{dl}$ & Ref $0,51-0,95 \mathrm{mg} / \mathrm{dl}$ \\
\hline C-reactive protein (CRP) & $22 \mathrm{mg} / \mathrm{L}$ & Ref. $0,0-7,0 \mathrm{mg} / \mathrm{L}$ \\
\hline Carcinoembryonic Antigen (CEA) & $\mathrm{I}, 94 \mu \mathrm{g} / \mathrm{L}$ & Ref. $0,00-5,0 \mu g / L$ \\
\hline ACTH* & $19,0 \mathrm{pg} / \mathrm{ml}$ & Ref. $7,2-63,3 \mathrm{pg} / \mathrm{ml}$ \\
\hline Cortisol & $936,2 \mathrm{nmol} / \mathrm{L}$ & Ref. I33-537nmol/L \\
\hline Aldosterone & $1004 \mathrm{pg} / \mathrm{ml}$ & Ref. (supine) $68-173 \mathrm{pg} / \mathrm{ml}$ \\
\hline Renin & $544,9 \mathrm{pg} / \mathrm{ml}$ & Ref. (Ih supine) $2,4-21,9 \mathrm{pg} / \mathrm{m}$ \\
\hline PAC/ARC ratio** & $\mathrm{I}, 8$ & I \\
\hline IgA-tissue transglutaminase antibody & $0,9 \mathrm{AU} / \mathrm{ml}$ & Ref. $0,00-\mid 5,0 \mathrm{AU} / \mathrm{ml}$ \\
\hline
\end{tabular}

$S D$, standard deviation; $B M I$, body mass index;WC, waist circumference; $A C$, abdominal circumference; $H C$, hip circumference; RER, respiratory exchange ratio; $H R$, hear rate.

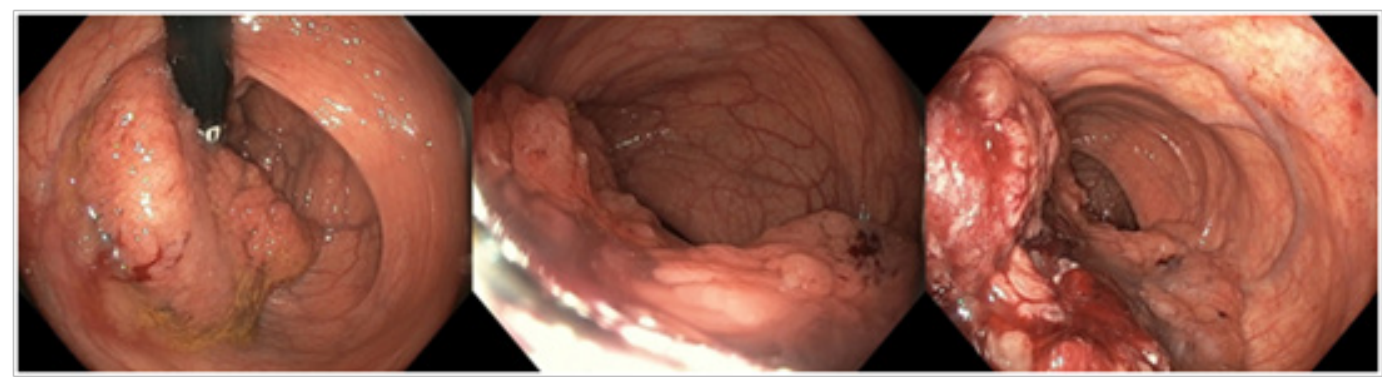

Figure I Colonoscopy with retrovision and antevision in the rectum showing a large villous adenoma, spreading semi-circumferentially along the rectal wall.

\section{Discussion}

\section{Definition, clinical presentation and treatment}

MWS is a rare disorder that was first described in 1954. It is defined by the triad of electrolyte disorders, kidney injury secondary to fluid depletion and chronic secretory diarrhea caused by a large rectal neoplasm. ${ }^{1-10}$ Renal adaption and increased oral intake may initially compensate for the fluid and electrolyte losses. In this way, mucinous diarrhea may exist for a long time (even years) before presentation. Eventually, as the polyp grows and the amount of diarrhea augments, compensatory mechanisms become exhausted and life-threatening complications can develop due to electrolyte disturbances and hypovolemia. ${ }^{1,4,7}$ In addition adenoma's can degenerate into an adenocarcinoma. The majority of McKittrick-Wheelock syndromes are due to large $(>3-4 \mathrm{~cm})$, mucus-rich villous adenoma in the distal part of the colon..$^{1-4,7}$ In a recent case review performed by Sarthak 
M et al., ${ }^{1}$ out of 35 found cases 22 had a villous adenoma, 8 had an underlying adenocarcinoma, one had a hyperplastic polyp and one had a neuro-endocrine tumor with liver metastases. In 3 cases, the histological details were not available. ${ }^{1}$ Hashash JG et al. ${ }^{4}$ also mention one case due to an incarcerated rectal prolapse. ${ }^{4}$

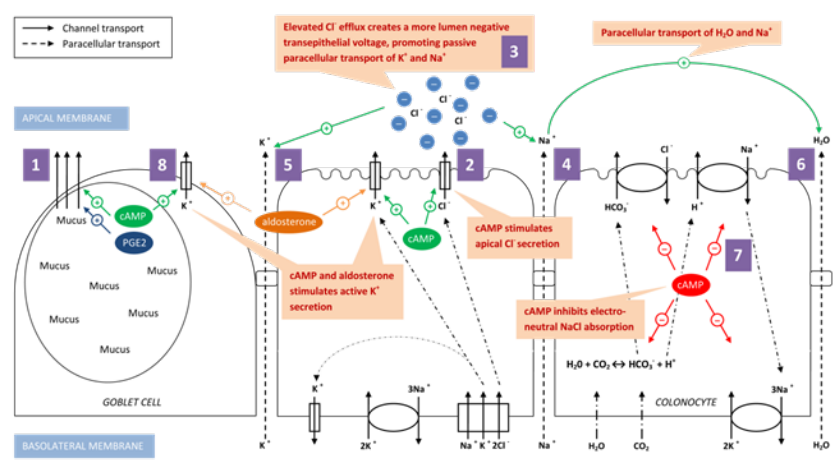

Figure 2 Hypothesis of the pathophysiological mechanism of McKittrickWheelock syndrome. (I) Goblet cells producing mucus, stimulated by cAMP and PGE2. (2) cAMP stimulates apical $\mathrm{Cl}$ - secretion in colonocytes. (3) Elevated $\mathrm{Cl}$ - efflux creates a more lumen negative transepithelial voltage promoting passive paracellular transport of $\mathrm{Na}+(4)$ and $\mathrm{K}+(5)$. (6) $\mathrm{H} 2 \mathrm{O}$ is paracellular transported together with the paracellular $\mathrm{Na}+$ transport. (7) cAMP inhibits electroneutral $\mathrm{NaCl}$ absorption. (8) Active $\mathrm{K}+$ secretion is stimulated by cAMP and aldosterone, predominantly in goblet cells. All these mechanisms contribute to the excessive loss of fluid and electrolytes in the McKittrickWheelock syndrome.

cAMP, cyclic adenosine monophosphate; PGE2, prostaglandin E2; $\mathrm{K}+$, potassium; $\mathrm{Cl}-$, chloride; $\mathrm{Na}+$, sodium; $\mathrm{HCO} 3-$, bicarbonate; $\mathrm{H}+$, hydrogen; $\mathrm{H}_{2} \mathrm{O}$, dihydrogen Monoxide (water); $\mathrm{CO}_{2}$, carbon dioxide

Patients most commonly present with mucinous diarrhea, dehydration, renal insufficiency, symptomatic electrolyte disturbances (severe hypokalemia, severe hypo-osmotic hyponatremia, hypochloremia with low urinary chloride (Cl-) concentration and metabolic acidosis or metabolic contraction alkalosis) ${ }^{1,4,6-8}$ Hyperglycemia and new-onset diabetes are very rare complications. ${ }^{5}$ Other complications and comorbidities reported in literature include pseudo-obstruction, intussception, rectal prolapse, rhabdomyolysis, Clostridium difficile induced diarrhea and endocarditis. ${ }^{1}$ Untreated MWS can lead to a mortality of $100 \%$. However, if treated correctly and in time, the condition should be completely reversible. ${ }^{2,5}$

First step in treatment should involve aggressive fluid resuscitation and correction of electrolyte and metabolic disturbances. ${ }^{1,5}$ Some authors have proposed pharmacological treatment with nonsteroidal anti-inflammatory agents (NSAIDS), inhibitors of the cyclo-oxygenase-2 (COX-2) pathway, somatostatin analogues and indomethacin as inhibitors of prostaglandin synthesis to reduce mucus and fluid secretion. ${ }^{1,5,8,12}$ The evidence for this medical treatment however remains anecdotal and use of NSAIDS for treating a syndrome witch renal insufficiency is not opportune.

Once the patient is stabilized, the polyp must be removed by surgical or endoscopic resection. Due to the low number of published cases, data on recurrence and long term prognosis is not well documented. So far, no recurrence after surgical resection has been described.

\section{Pathophysiology}

The exact pathophysiological mechanism of MWS is not fully understood. After reviewing the literature, we propose the following hypothesis (Figure 2). Independent of the type of polyp, the key element in the development of all MWS cases is the secretion of fluids and electrolytes. Fluid losses up to 4 liters a day are reported. Characteristic for MWS is that the fluid depletion is caused by the polyp itself and its typical distal location in the colon. This is in contrast to other causes of secretory diarrhea such as infectious diarrhea in which a larger part of the entire intestine can be involved (e.g. Cholera toxin).

Secretory villous adenomas, in contrast to non-secretory villous adenomas, contain multiple goblet cells producing mucus. ${ }^{9}$ The mucus production can be mediated by cyclic adenosine monophosphate (cAMP) and stimulated by secreatagogues such as prostaglandins, cytokines and neuropeptides. ${ }^{13}$ Elevated levels of cAMP, adenylate cyclase and prostaglandin E2 (PGE2) have been found in rectal effluents of patients with secretory villous adenoma. ${ }^{12}$

This mucus discharge explains only partially the large amount of fluid loss. A second mechanism is located on a cellular level and involves paracellular excretion of water through the colonic epithelium in response to changed electrolyte fluxes (cfr. infra). A third important contributing factor is the distal location of the polyp in the colon. This location inhibits compensatory reabsorption due to the reduced surface area of normal colonic mucosa below the lesion. This makes the diarrhea persist with fasting and explains why only rectal and distal colonic lesions can lead to development of MWS. ${ }^{1,2,5,6}$ The electrolyte disturbances can be explained on a cellular and molecular level. Cl- secretion through the $\mathrm{Cl}$ - channel at the apical membrane of the colonic epithelium can be stimulated by elevated levels of cAMP. ${ }^{14-17}$ Elevated Cl- secretion will in turn stimulate intraluminal loss of sodium $(\mathrm{Na}+)$ since the increased $\mathrm{Cl}$ - efflux creates a more lumen negative transepithelial voltage, which promotes paracellular secretion of $\mathrm{Na}+$ and water. ${ }^{14,15}$ Furthermore, the electroneutral $\mathrm{NaCl}$ absorption by the dual $\mathrm{Na}+/ \mathrm{H}+$ and $\mathrm{Cl}-/ \mathrm{HCO}_{3}$ - exchange pumps at the apical membrane of the colonic epithelium is dependent on cAMP activity. Elevated levels of cAMP will therefore also reduce this $\mathrm{NaCl}$ absorption. ${ }^{15,18}$

The most important electrolyte disturbance in MWS is hypokalemia. Both active and passive potassium $(\mathrm{K}+)$ secretion and active $\mathrm{K}+$ absorption takes place in the distal colon. In normal circumstances, the final net result favours $\mathrm{K}+$ secretion in the stool. In MWS, active and passive $\mathrm{K}+$ secretion is increased. The passive transport of $\mathrm{K}+$ is predominantly paracellular, driven by a negative transepithelial voltage. Therefore, the increased cAMP mediated $\mathrm{Cl}-$ efflux promotes passive efflux of $\mathrm{K}+$. Active $\mathrm{K}+$ secretion is mediated by an apical $\mathrm{K}+$ channel. Histopathological examination of a secretory villous adenoma showed over-expression of the apical $\mathrm{K}+$ channel. $^{19}$ Linley et al. ${ }^{20}$ postulate that $\mathrm{K}+$ channels in the colon originate from goblet cells while the $\mathrm{Cl}$ - secretion through apical $\mathrm{Cl}$ - channels is dedicated to the colonocytes. ${ }^{20}$ This finding is compatible with the profound $\mathrm{K}+$ loss in MWS since goblet cells are numerous in secretory villous adenomas. ${ }^{9}$ Activation of these apical $\mathrm{K}+$ channels can be stimulated by elevated levels of cAMP but also by elevated levels of aldosterone..$^{15}$ As our case shows, secondary hyperaldosteronism can develop due to activation of the RAAS system in response to the intravascular volume depletion and sodium loss. Besides, elevated aldosterone levels will also stimulate renal $\mathrm{K}+$ excretion in the distal tubules and collecting ducts of the nephron.

The mechanism of glucose intolerance in MWS remains unclear. Some evidence suggest a causal association with hyperaldosteronism and/or total body $\mathrm{K}+$ depletion. Hyperaldosteronism may contribute to impaired glucose tolerance. Hypokalemia can cause dysregulated 
insulin secretion by attenuating ATP generation and may act in synergy with hyperaldosteronism to disrupt glucose homeostasis. ${ }^{5}$ Overall, all the above mentioned pathophysiological mechanisms can cause a vicious circle of profound electrolyte and fluid loss for which the homeostasis mechanisms at a certain moment fail to compensate and hence, development of the McKittrick-Wheelock syndrome occurs.

\section{Conclusion}

It is imperative that the MWS is included in the work up of chronic diarrhea. If missed, this condition can lead to detrimental outcomes. However, if treated adequately, MWS is a curable condition. In case of a triad of chronic diarrhea, electrolyte disorders and renal insufficiency, a distal colon adenoma should always be considered.

\section{Acknowledgments}

Jeroen Geldof and Alexander Vanden Bulcke contributed in the same amount in the creation and writing of this paper and are both regarded as first author. All authors managed the patient during the hospitalization. All authors critically revised and approved the submitted version of this paper.

\section{Conflicts of interest}

The authors declare there is no conflict of interests.

\section{Funding}

None.

\section{References}

1. Malik S, Mallick B, Makkar K, et al. Malignant McKittrick-Wheelock syndrome as a cause of acute kidney injury and hypokalemia: report of a case and review of literature. Intractable Rare Dis Res. 2016;5(3):218221.

2. Popescu A, Orban-Schiopu AM, Becheanu G, et al. McKittrickWheelock Syndrome - a Rare Cause of Acute Renal Failure. Rom J Gastroenterol. 2005;14(1):63-66.

3. Ohara Y, Toyonaga T, Watanabe D, et al. Electrolyte depletion syndrome (McKittrick-Wheelock syndrome) successfully treated by endoscopic submucosal dissection. Clin J Gastroenterol. 2015;8(5):280-284.

4. Hashash JG, Holder-Murray J, Aoun E, et al. The McKittrick-Wheelock syndrome: a rare cause of chronic diarrhea. BMJ Case Rep. 2013.

5. Challis BG, Lim CT, Cluroe A, et al. The McKittrick-Wheelock syndrome: a rare cause of curable diabetes. Endocrinol Diabetes Metab Case Rep. 2016:160013.
6. Agnes A, Novelli D, Doglietto GB, et al. A case report of a giant rectal adenoma causing secretory diarrhea and acute renal failure: McKittrickWheelock syndrome. BMC Surg. 2016;16(1):39.

7. Raphael MJ, McDonald CM, Detsky AS. McKittrick-Wheelock syndrome. CMAJ. 2015;187(9):676-678.

8. Lepur D, Klinar I, Mise B, et al. McKittrick-Wheelock syndrome: a rare cause of diarrhea. Eur J Gastroenterol. Hepatol 2006;18(5):557-559.

9. Older J, Older P, Colker J, et al. Secretory villous adenomas that cause depletion syndrome. Arch Intern Med. 1999;159(8):879-880.

10. Samaey P, De Schoenmakere G, Schepkens H, et al. Een zeldzame oorzaak van levensbedreigend acuut nierfalen. Tijdschrift voor geneeskunde. 2014;70(3):156-161.

11. Edge SB, Byrd DR, Compton CC, et al. AJCC cancer staging handbook: from the AJCC cancer staging manual.(7), Springer-Verlag New York, 175 Fifth Avenue, New York, New York 10010 United states of America; 2010. 718 p.

12. Steven K, Lange P, Bukhave K, et al. Prostaglandin E 2-mediated secretory diarrhea in villous adenoma of rectum: effect of treatment with indomethacin. Gastroenterology. 1981;80(6):1562-1566.

13. Kim YS, Ho SB. Intestinal goblet cells and mucins in health and disease: recent insights and progress. Curr Gastroenterol rep. 2010;12(5):319330 .

14. Frizzell RA, Hanrahan JW. Physiology of epithelial chloride and fluid secretion. Cold Spring Harb perspect in medicine. 2012;2(6):a009563.

15. Binder HJ. chapter 43: Intestinal fluid and electrolyte movement. In: Boron WF, Boulpaep EL, eta 1. (EDS.), Medical physiology (2003). Elsevier saunders, The Curtis center, 170 S independence Mall W 300E, Philadelphia, Pennsylvania 19106, United states of America; 2003:931946

16. Fujii S, Suzuki K, Kawamoto A, et al. PGE2 is a direct and robust mediator of anion/fluid secretion by human intestinal epithelial cells. Sci Rep. 2016;6:36795.

17. Karaki SI, Kuwahara A. Regulation of intestinal secretion involved in the interaction between neurotransmitters and prostaglandin E2. Neurogastroenterol Motil. 2004;16(s1):96-99.

18. Sandle GI. Salt and water absorption in the human colon: a modern appraisal. Gut. 1998;43(2):294-299.

19. Sandle GI, Hunter M. Apical potassium (BK) channels and enhanced potassium secretion in human colon. $Q \mathrm{~J} \mathrm{Med}$. 2010;103(2):85-89.

20. Linley J, Loganathan A, Kopanati S, et al. Evidence that two distinct crypt cell types secrete chloride and potassium in human colon. Gut. 2013;63(4):472-479. 